\title{
Flexible Labor Regulations and Informality in Egypt*
}

\author{
Jackline Wahba ${ }^{1}$ and Ragui Assaad ${ }^{2}$
}

July 2016

\begin{abstract}
Do more flexible labor market regulations reduce informal employment in formal firms? This paper examines the effects of changes in labor regulations on the incidence of formal employment. Using the case of Egypt, we study the effects of the introduction of more flexible labor regulations in 2003 on the probability that noncontractual workers will be granted a formal employment contract. To identify the effect of the law and control for potential confounding factors, we use a difference-indifference estimator that measures the difference in the pre and post-law probability of obtaining a formal contract across a treatment group of non-contractual workers initially employed in formal firms and a comparison group of non-contractual workers initially employed in informal firms. The latter serve as a useful comparison group since informal firms are unlikely to formalize as a result of the law, so that the only way their workers can become formal is to move to another firm. Our findings show that the passage of the new labor law did in fact increase the probability of transitioning to formal employment for non-contractual workers employed in formal firms by about 3-3.5 percentage points, or the equivalent of at least a fifth of informal workers in formal firms.
\end{abstract}

\footnotetext{
${ }^{1}$ Department of Economics, University of Southampton, UK. Email: j.wahba@soton.ac.uk.

${ }^{2}$ Humphrey School of Public Affairs, University of Minnesota. Email: assaad@umn.edu.

*Financial support from the Economic Research Forum (ERF) is gratefully acknowledged.
} 


\section{Introduction}

Labor market regulations have significant impacts on the functioning of labor markets affecting the rate of job creation and destruction, the levels of employment and unemployment in the economy, and the degree of social protection provided to workers. However, there is wide disagreement among economists on the costs and benefits of labor market regulations. While some economists believe that regulated labor markets distort labor outcomes, others argue that regulations are needed to protect poor and vulnerable workers. ${ }^{3}$

Labor market regulations may affect labor market outcomes by affecting the choices of firms over inputs and by influencing the allocation of resources across firms and sectors of the economy. Thus the role played by labor regulations, and whether they help or hinder labor reallocation, is important in particular for developing countries since, as argued by Boeri et al. (2008), poorer countries might have stricter labor laws compared to richer countries, even though they offer less social protection. Also strict labor regulations are often associated with a larger informal economy, worse working conditions and poor job quality. Thus, an important issue is whether stricter regulations increase labor informality. This paper aims to examine whether strict labor regulations lead to a larger informal sector. More, precisely, it studies whether the introduction of more flexible labor regulations promotes the formalization of employment.

In order to better understand the causal impact of strict labor regulations on formalization, we use the enactment of the 2003 labor law in Egypt to study the impact of increased flexibility in job protection regulations on the incidence of informal employment. The new labor law (Law No. 12 of 2003) provided increased flexibility for firms in the hiring/firing process, which is believed to have been a major bottleneck for the formal reporting or registration of jobs among formal firms in MENA labor markets, including those in Egypt. ${ }^{4}$

We use this natural experiment to evaluate the impact of more flexible employment protection legislation on the formalization of private wage employment. This is an important issue for developing countries, like Egypt, where informal employment has been growing over the last few decades and has become the main form of employment in the economy as public sector employment contracts (Assaad and Krafft 2015). Informal employment tends to be of low quality with no job security and no social insurance coverage. From a policy perspective, it is essential to investigate whether more flexible labor regulations do indeed encourage the formalization of employment in the private sector, leading to more protected jobs.

We use parametric and non-parametric techniques to estimate the effects of the policy change on the incidence of acquiring formal job contracts in the private sector. To obtain an estimate of the causal impact of the law and controlling for potential confounding factors such as the business cycle, we adopt a difference-in-difference approach that exploits the temporal change in law and the variation across employers' formality status. We argue that non-contracted workers who work for formal or semiformal employers, where other co-workers are contracted and covered by social insurance, would be directly affected by the change in law. On the other hand, noncontracted workers working for informal employers, where all other co-workers have no job contracts and no social security coverage, would only be affected by the law, indirectly by moving to jobs in formal firms, since their employers are unlikely to

\footnotetext{
${ }^{3}$ See Freeman (1993) for a summary of this debate.

${ }^{4}$ Angel-Urdinola and Kuddo 2010, Gatti et al. 2011, p. 138-152.
} 
become formal as a result of the law. We confine our analysis to the period between 1998-2008 to construct 5-year periods before and after the law. Our findings indicate that the acquisition of new contracted jobs has increased in formal and semi-formal firms compared to informal firms by about 3-3.5 percentage points after the introduction of the new law. Since, the baseline estimate of non-contracted jobs in formal firms is $0.017 \%$, this represents a relative decrease of informality in formal firms of $200 \%$. Thus, our findings support the hypothesis that the introduction of less rigid labor market regulations increases the formalization of employment.

The structure of the paper will be as follows. Section 2 reviews the previous literature dealing with labor market regulations focusing on the effect of employment protection regulations. Section 3 provides a brief overview of the Egyptian labor market and describes the 2003 Labor Law. Section 4 examines trends and patterns of informality in Egypt. Section 5 presents the empirical analysis of the impact of the 2003 labor law. Section 6 concludes.

\section{Theoretical Background and Literature Review}

There is an extensive debate among economists on the costs and benefits of labor market regulations. Some economists believe that unregulated labor markets are more efficient than regulated ones. They argue that labor market regulations introduce distortions that misallocate labor; waste resources through rent-seeking, impede adjustments to economic shocks, discourage hiring, and favor "insiders" (such as regular workers or males) and therefore reduce growth. Freeman (1993) refers to that view as the "distortionist" view. On the other hand, others believe, the "institutionalist" view, that due to market failure and the ensuing injustice and inequity, regulations are needed to protect poor and vulnerable workers. ${ }^{5}$

There are various forms of labor regulations. In general, labor market regulations are introduced with the objective of protecting workers from uninsurable labor market risk, such as employment risk, or from earnings risk. To improve the earnings of the most disadvantaged categories of workers, governments typically set minimum wages; they might also mandate that employers provide non-wage benefits to their workers, such as healthcare, paid vacation, maternity leave, etc. To protect workers from employment risk, governments can decide to protect existing jobs by restricting the ability of firms to lay off workers at will and/or provide unemployment insurance to those who lose their job (Boeri et al. 2008).

In this paper, the focus is on employment protection rules; namely hiring and firing arrangements affecting job security. These include issues like what types of contracts are allowed, the conditions under which workers' contracts can be terminated, requirements for severance and advance notice of termination, redundancy procedures, and special rules for mass layoffs.

There has recently been a move toward labor market flexibility and the introduction of labor market reforms to enhance productivity and competition, and to accelerate employment generation and improve economic performance. Yet the empirical evidence on the effects of labor flexibility is mixed, see for example, Boero et al. (2008) and Di Tella and MacCulloch (2009). The main empirical evidence on the effect of labor market flexibility has focused mainly on developed countries, but has more recently included studies on developing countries as well. For example, Boeri et al

\footnotetext{
${ }^{5}$ See Freeman (1993) for a summary of this debate.
} 
(2008) argue that poorer countries tend to have stricter labor regulations compared to richer countries, even though they offer less social protection. Also the World Bank in its report Doing Business 2009 shows that developing countries tend to mistakenly go to the extreme of rigid regulations, pushing employers and workers into the informal sector (World Bank 2009). Overly rigid regulations may have undesirable effects such as lower job creation, smaller company size, less investment in research and development, and longer spells of unemployment and thus the obsolescence of skills, all of which may reduce productivity growth. Hence, excessive rigidity can be to the detriment of businesses and workers alike. Djankov and Ramalho (2009) summarize the effect of employment laws in developing countries based on studies published since 2004 and supported by cross-country correlation analyses based on data from the World Bank Doing Business reports, conclude that developing countries with rigid labour regulations tend to have larger informal sectors and higher unemployment. Obviously, the effectiveness of labor regulations will depend on the extent to which those regulations are enforced.

The degree of rigidity of employment protection rules can affect labor market outcomes such as employment levels, employment adjustment, and the composition of employment, see for example Lazear (1990). The theoretical impact of strict termination rules can be summarized as follows: lower labor turnover rates (hirings plus separations); lower aggregate employment levels; greater numbers of long-tenure jobs; lower labor force participation rates; no clear impact on unemployment levels, but longer average unemployment durations; at a macro level, slower recovery from an aggregate shock; more self-employment as a share of total employment; more nonstandard employment (e.g., part-time or temporary); positive employment effects for insiders. ${ }^{6}$ For example, Bentolila and Bertola (1990) presenting a dynamic model featuring a monopolistic firm which faces idiosyncratic shocks and firing costs in a partial equilibrium setting where wages are exogenous show that firing costs will reduce job turnover and the volatility of employment and unemployment over the business cycle. Hopenhayn and Rogerson (1993) extending the above model in a general equilibrium setting predicts that increased firing costs will result in lower firm entry and job creation rates in an economy as a whole. Blanchard and Portugal (2001) using general equilibrium matching models in which wages are set as a result of bargaining between workers and employers, predict higher wages for insiders and lower employment rates than the efficient level; i.e. firing costs reduce turnover and increase the duration of unemployment.

A few studies have examined the effects of flexible labor market regulations in developing countries. Measuring the impact of employment protection in particular is challenging since job security rules are not easily transformed to a single number, in particular when comparing across countries. Although more recently, a few studies have used Doing Business Indicators, for example see (Djankov and Ramalho, 2009). Others have used monetary costs incurred by employer to comply with job security regulations as another measure. For example, Heckman and Pagés (2004) use the present value of the expected average cost at the time of hiring to the firm for dismissing a regular worker for economic reasons.

There is little causal evidence on the impact of labor regulations on employment in developing countries and limited understanding of the optimal degree of regulation. A few studies have examined the impact of labour regulations/flexibility in developing

\footnotetext{
${ }^{6}$ See Betcherman et al. (2001) Betcherman (2015) for a review on labor regulations.
} 
countries. Kingdon et al. (2006) show that the failure of African labor markets to create good paying jobs was the result of lack of labor market "flexibility", which kept formal sector wages above their equilibrium level and restricted job creation. This resulted in excess labor supply in the form of either open unemployment or a growing selfemployment sector.

Besley and Burgess (2004) examine the link between regulation and long-term development in India by looking at state amendments to the Industrial Disputes Act of 1947. They find that labor regulation is a key factor in the pattern of manufacturing development in India. Regulating in a pro-worker direction was associated with lower levels of investment, employment, productivity and output in registered manufacturing and with increasing informal sector activity. However, this paper does not look at employment protection law in particular, nor the causal impact of regulations.

Studies on Latin America tend to find negative evidence of job security rules on employment effects, see Heckman and Pagés (2004). This could be due to different methodologies but might also be driven by stricter employment protection in Latin American countries compared to OECD countries. For example, Kugler (2004) examines the impact of the Colombian labor market reform of 1990, which substantially reduced the costs of dismissing workers through the reduction of severance payments on unemployment. Using micro-level data from Colombia and the difference in coverage between formal and informal sector workers as a source of identification, she finds that those reforms contributed to $10 \%$ of the reduction in unemployment during the period of study.

This paper contributes to this literature by focusing on the case of Egypt and examining the impact of employment protection reforms on formalization of labor. An earlier study by Wahba (2009) found evidence of positive effects two years after the introduction of the law. However, it is important to examine the long-term effects and the sustainability of those effects. Hence, this paper, using richer data, examines the impact of the flexible employment law in a more rigorous manner using program evaluation techniques to disentangle the impact of the law from confounding factors.

\section{The 2003 Labor Law \& the Egyptian Labor Market}

First, we examine how the Egyptian labor market and in particular labor regulations in Egypt compare to other countries. The ease of doing business index of the World Bank's Doing Business report ranks countries against each other based on how the regulatory environment is helpful to business operations. Countries with a high rank on this index (1 to 20) have simpler and more business friendly regulations. According to this index Egypt ranked 141 among 155 countries in 2006, the first year in which the report provided overall countries rankings. It's ranking improved to 126 out of 178 countries in 2008, then to 106 out of 183 countries in 2010, but fell back to 131 out of 189 in 2016 due in part to the political instability and economic turmoil brought about by the 2011 uprisings.

From its start in 2004 and up to 2010, the Ease Doing Business index included a set of labour market indicators that varied from year to year but included some of the following: flexibility or difficulty of hiring, rigidity of hours, flexibility or difficulty of 
firing, rigidity or conditions of employment, and firing costs. ${ }^{7}$ We focus here on the difficulty/flexibility of firing and firing cost sub-indicators since those are the heart of the 2003/04 labour law reforms in Egypt. In 2004, the year in which the new labour law came into effect, Egypt ranked $119^{\text {th }}$ out of 133 countries on the flexibility of firing. Even three years after the new law came into effect, in 2007, Egypt ranked dead last among 175 countries on this measure, with an index value of 100 (the maximum level of rigidity). The firing cost was reported to be 186 weeks of salary on that year, placing Egypt in the $173^{\text {rd }}$ place. However, by 2008, the value of the difficulty of firing index for Egypt had fallen to 60, partially reflecting the legal reforms, and placing Egypt at a rank of 153 out of 178 countries, but firing cost only fell to 132 weeks, reducing Egypt's rank only slightly to 168 among 178 countries. There were no further changes in the value of Egypt's difficulty of firing or firing cost indicators in 2009 and 2010 Doing Business reports. Although, the report stopped creating labour market indices in 2011, it continued to report a number of labour market indicators including severance pay for redundancy dismissal, which is presumably a similar concept as firing cost. By the 2011 report, that indicator stood at 26.7 weeks of salary and stayed at that level until 2016. Since we know that no labour law changes were introduced in Egypt since 2004, the changes in the Doing Business data simply appears to reflect some inertia on the part of the World Bank data collection team in keeping up with the legal changes in Egypt.

\subsection{The Egyptian Labor Market Before the 2003 Law}

The Egyptian labor market had several important characteristics that originated back in the early 1960s when the government passed a law that guaranteed employment to all secondary, technical institutes and university graduates to encourage education and to meet its needs for trained cadres in the context of a state-led development strategy. Over time, this policy led to an overstaffed public sector and a highly segmented labor market (Assaad 2009). From the 1960s to the 1980s, the Egyptian public sector was the main creator of employment opportunities and typically the preferred sector by most new entrants to the labor market. The economic reforms of the 1990s curbed new employment opportunities in the public sector and initiated a privatization program for existing state-owned enterprises, but the size of the private formal sector has continued to be small. As a result, unemployment rates among the new entrants to the labor market increased. At the same time, the role of the private formal sector in job creation continued to be very limited, resulting in an increase of informal employment, where jobs are not covered by social insurance or legal employment contracts, see Mokhtar and Wahba (2000), Assaad (2009), Gatti et al (2011) and Assaad and Krafft (2015).

The labor law in force throughout the 1980s and 1990s (Law 137 of 1981) included some very strict job protection provisions, which were retained from previous versions of the labor laws, such as Law 91 of 1959. Dismissal for cause was very difficult to achieve and was subject to judicial approval upon the advice of a tri-partite committee representing employers, unions and the judiciary. Indefinite duration contracts could not be terminated by employers for economic reasons after a three-month probation period short of permanent and complete liquidation of the firm. Definite duration contracts could only be issued once and were automatically transformed into indefinite

\footnotetext{
${ }^{7}$ The Doing Business report stopped ranking countries based on this index and stopped including labour market indicator in the Ease of Doing Business index in 2011. Since then, they have simply provided an ever expanding set of labour market information for each country.
} 
duration contract upon renewal (Assaad 2004). According to Article 30 of Law 137 of 1981, all employment contracts, whether indefinite or definite duration, must be me made up of three copies, one to be kept in the worker's folder held by the employer, one for the worker, and one to be deposited with the relevant social insurance office. This feature has been retained in the new law (Law 12 of 2003).

With imperfect enforcement, most formal private sector firms simply eluded the strict job security provisions of Law 137 of 1981 and its predecessors by not providing a substantial proportion of their workers with legal work contracts or reporting them to the social insurance administration. The proportion of informal workers (those with neither a contract nor social insurance) in private firms of 25-49 workers was 44 percent in 1998 and 49 percent in 2006. In firms of one hundred workers and above, that proportion fell to just 20 and 19 percent respectively (Assaad and Krafft 2015).

\subsection{The Egyptian Labor Market After the 2003 Law}

The new labor law (Law 12 of 2003) was passed with the goal of increasing flexibility of hiring/firing in the private sector and in state-owned enterprises. The law that came into effect in early 2004 and is comprised of 257 articles that address all the legal aspects regulating the Egyptian labor market by providing comprehensive guidelines for the recruitment, hiring, compensation, and termination of employees. The most important change the new law introduced was to allow definite duration contracts to be renewed an unlimited number of times. For example, instead of providing an indefinite duration contract, employers could provide a series of one-year contracts ad infinitum, giving them the right to terminate employment at the conclusion of the one-year term. In the previous law, a definite duration contract was immediately converted into an indefinite duration contract if the worker was retained after the conclusion of the term of the contract. Another important stipulation of the 2003 law is that indefinite duration contracts could be terminated with the approval of a Stoppage Committee established by prime ministerial decree, subject to the payment of severance pay ranging from one to one and half months per year of service, depending on the length of service. All workers whose employment began prior to the new law coming into effect were grandfathered in under the old rules, so that the new rules only applied to workers hired since 2004. The rules for dismissal for cause were slightly modified to make such dismissal subject to the approval of Judicial Committee without the need to undertake a lengthy judicial process (Assaad 2004)

The new law does not apply to public employees in central and local government and public authorities. As part of a quid pro quo with labor unions, the new law introduced a limited right to strike. Local union committees would be authorized to organize strike actions subject to the approval of two-thirds of the governing board of the relevant national union federation.

Given the added flexibility, the 2003 law provides employers by allowing them to issue definite duration contracts and renew them any number of times and to lay off workers for economic reasons, subject to payment of severance pay, our hypothesis is that formal private sector employers will be willing to hire more workers formally after the passage of the law. Although enforcement is still likely to be imperfect after the enactment of the law, eluding labor regulations is costly to employers since it requires the payment of bribes to labor inspectors and causes other bureaucratic hassles. Thus as the cost of formality falls for employers, it is likely that they will respond by formalizing more of their workers. In the following section, we test this hypothesis by determining whether the passage of the new law has led to a higher incidence of contracted workers in the formal private sector. 


\section{Informalization and Job Contract Holding}

\subsection{Data}

The analysis in this paper uses data from the Egypt Labor Market Panel Survey of 2012. The ELMPS 2012 is the third wave of a periodic longitudinal survey that tracks the labor market and the demographic characteristics of households and individuals over time, with the previous waves carried out in 1998 and 2006 (ERF 2012). The fieldwork for the ELMPS 2012 was carried out from March to June of 2012. ${ }^{8}$ The survey was carried out by the Economic Research Forum (ERF) in cooperation with the Egyptian Central Agency for Public Mobilization and Statistics (CAPMAS) - the main statistical agency of the Egyptian government. The final sample of the ELMPS 2012 was 12,060 households containing a total of 49,186 individuals. We do not rely on the panel feature of the dataset but rather on the rich retrospective information about respondents' employment histories.

The survey's job mobility module includes detailed information about five consecutive employment statuses, including both jobs and non-employment states, starting from the first status after leaving school and moving chronologically to the fourth status. The year and month of start of each status is recorded, enabling us to construct job and non-employment spells. Statuses that last for a duration shorter than six months are dropped by design. Detailed information about the current status is also collected. For each status that involves an employment state, the survey enquires about all the usual job characteristics, including employment status (wage work, selfemployment, etc.), occupation, economic activity, sector (public, private, etc.), and size of enterprise. For each job status, workers are also asked about whether the job was covered by social insurance and a legal contract, if covered by a contract, the type of contract involved (indefinite vs. definite duration). If workers do report having a contract or social insurance coverage, they are asked whether the contract or social insurance coverage started with the start of the job or whether it was acquired later, and if the latter, how much later. Workers who report not having a contract of social insurance coverage in a particular job are asked if any other workers in the enterprise where they worked had contracts or social insurance coverage. We use this information to determine whether the firm in which the worker worked is itself formal or informal, irrespective of the formality status of his/her own job.

Given that the change in the labor law applies only to the private ${ }^{9}$ non-agricultural sector and only waged workers may hold contracts (i.e. self-employed workers and employers do not hold job contracts), the focus of this paper will be on private nonagricultural waged work. The aim of the paper is to test whether the 2003 labor law affected the incidence of job contract acquisition among private non-agricultural waged workers. For the rest of the paper, informality refers to lack of a legally registered job contract while formality refers to holding a job contract, unless otherwise mentioned. We confine our sample to those 18-55 years of age throughout our analysis.

One concern with the reliance on recall data on employment histories for the measurement of employment transitions between 1998 and 2008, is the biased resulting from re-calling older dates. However, given that securing a job contract is very

\footnotetext{
${ }^{8}$ See Assaad and Krafft (2013) for a detailed description of the survey and the data set.

${ }^{9}$ Public sector employees are generally protected: the vast majority of them hold legal job contracts or appointments and have social security coverage, in addition to other benefits.
} 
important in terms of security and stability as well as its implications for social security coverage and other benefits it is less likely to be forgotten by an employee. ${ }^{10}$ Nevertheless, the fact that we control for time trends in our estimates and our differencing strategy are ways to alleviate this concern. Since recall bias would translate into a secular time trend in formalizations, the inclusion of time trends and differencing could eliminate it, under the assumption that the trend is parallel between treatment and control groups.

\subsection{Informality Patterns and Trends}

First, in order to set the scene and place the group of interest in context, we present the patterns and trends of the distribution of employment by institutional sector between 1998, 2006 and 2012 using cross sectional data from the three waves of the survey. Figure 1 shows that the share of formal private regular work has increased from $6 \%$ in 1998 to $8 \%$ in 2006 to $10 \%$ in $2012 .{ }^{11}$ Informal private regular work has increased from 10\% in 1998 to 14\% in 2006 and then stayed at that level through 2012, while irregular (casual) wage work increased dramatically from 6\% in 2006 to 15\% in 2012, a reflection of the economic crisis Egypt was experiencing in 2012 in the aftermath of the January $25^{\text {th }} 2011$ revolution. So, what is interesting for us is that the private formal regular work has increased, although is still a small proportion of total employment. We investigate below to what extent this increase in formalization is caused by the 2003 labor law.

Zooming in on the Private Non-Agricultural Waged sector and examining the incidence of informality (defined as lack of job contract and social security coverage), between 1998 and 2012, we can see a slight decline in 2006, but a larger decline by 2012 for regular waged work. As for the share of those not holding contracts, this has decreased between 1998 and 2012, but more so for the regular waged workers. Admittedly, this could be due to selection effect resulting from the fact that the most precarious of these regular jobs dropped out of the category by being transformed into irregular jobs. Overall, Table 1 suggests that informality, defined as having either a contract or social insurance, has declined from 1998 to 2006, but not from 2006 to 2012, unless we only limit our attention to regular workers. Similar patterns can be observed for waged jobs without legal contracts.

\footnotetext{
${ }^{10}$ An analysis of the reliability of the retrospective data compared to the panel data revealed that respondents tended to under-report past non-employment spells, but that the characteristics of employment spells were fairly well captured. The distinction between regular and irregular formal employment is hard to capture in retrospective data, but the distinction between formal and informal employment is captured reasonably well. See Assaad, Krafft and Yassine (2015).

${ }^{11}$ Regular waged work refers to permanent or temporary work, whilst irregular waged work refers to seasonal and casual work. All work includes both regular and irregular waged work.
} 
Figure 1: Distribution of Employment by Institutional Sector, Currently Employed, 1998-2012

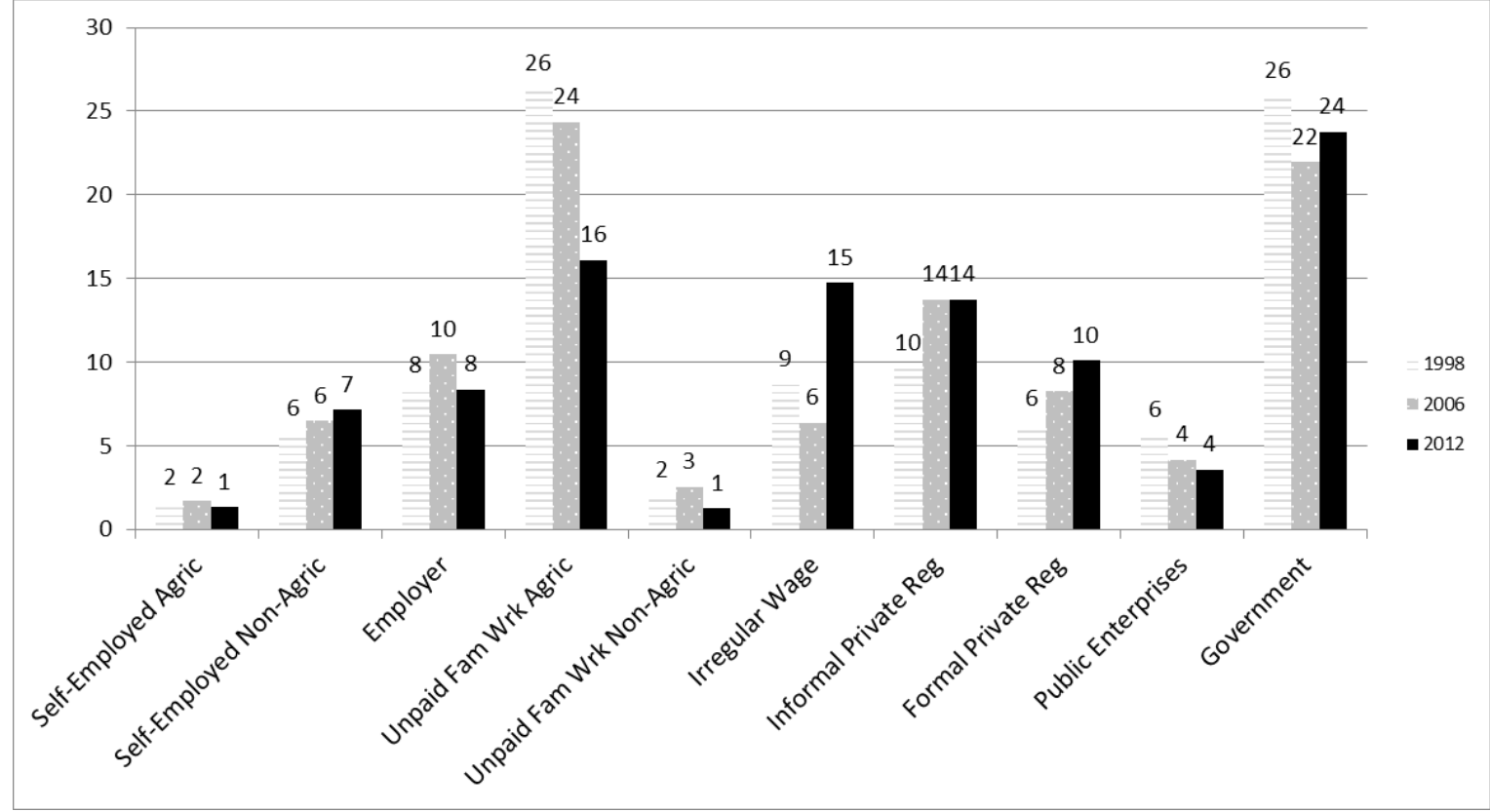

Note: Using cross sectional data from the three waves of the ELMPS survey: 1998, 2006 and 2012. Each wave adds to $100 \%$, and shows the distribution of employment across institutional sectors.

Table 1: Informality Share (\%) in Private Non-Agricultural Sector $1998-2012$ (18-59 years of age)

\begin{tabular}{l|rrr|rrr}
\hline & \multicolumn{3}{|c|}{ Informal Employment } & \multicolumn{3}{c}{ No Contract Holding } \\
& \multicolumn{3}{|c|}{$\boldsymbol{\%}$} & & \multicolumn{4}{c}{ \% } \\
\hline & $\mathbf{1 9 9 8}$ & $\mathbf{2 0 0 6}$ & $\mathbf{2 0 1 2}$ & $\mathbf{1 9 9 8}$ & $\mathbf{2 0 0 6}$ & $\mathbf{2 0 1 2}$ \\
\hline Private Non-Agricultural Waged $^{1}$ & 67.9 & 66.1 & 67.7 & 78.5 & 73.9 & 75.3 \\
& & & & & & \\
$\begin{array}{l}\text { Private Non-Agricultural Regular } \\
\text { Waged }^{2}\end{array}$ & 61.5 & 61.6 & 56.1 & 71.5 & 68.7 & 64.0 \\
\hline
\end{tabular}

Note: ${ }^{1}$ Private Non-Agricultural Waged (PNAW): includes all waged work, permanent, temporary, seasonal and intermittent employment. ${ }^{2}$ Private Non-Agricultural Regular Waged (PNARW): includes regular waged work only: both permanent and temporary.

In the analysis, below we focus on the period 1998-2008, for two reasons. Firstly, we want to construct two periods of equal length before and after the change in law. The law was announced in 2003 and became effective in 2004. So, our pre-law period is 1998-2002 and the post-law period is 2004-2008. We do not include 2003 because of anticipation effects, though our results are robust to including 2003 in the pre-policy period. Secondly, given the 2011 uprisings, we limit our focus to well before these events took place. This choice of period also allows us to abstract away from the effects of the world financial crisis on the Egyptian labor market, which started to be felt from 2009 onward (See Roushdy and Gadallah 2011). 
Table 2 shows the proportion of jobs that started between the years 1998-2002 that acquired contracts, relative to those jobs that started during the 2004-2008 period. The results suggest that this proportion may have increased by 2 to 3 percentage points from the pre-law to the post-law period, irrespective of whether we look at first jobs only or all job changes. Interestingly, this pattern is witnessed not only among workers moving to new jobs and thus changing employers but also among those who stayed with the same employer. Around 13\% of those who previously had no contract but acquired one, gained the contract while remaining with the same employer i.e. only changed contract status but stayed with the same employer. Of those who gained contract while with the same employer, two thirds have gained contracts between 2004-2008 and only a third did so in the earlier period (1998-2002). On average, the acquisition of contract with the same employer took 2.75 years.

Table 2: Percentage Acquiring Contract Among Private Agricultural Wage Workers: 1998-2002 vs 2004-2008

\begin{tabular}{l|cc}
\hline & $\mathbf{1 9 9 8 - 2 0 0 2}$ & $\mathbf{2 0 0 4 - 2 0 0 8}$ \\
\hline New Employer* & & \\
Regular waged jobs & 30.1 & 33.0 \\
Regular waged jobs: First Jobs & 37.4 & 39.5 \\
& & 27.3 \\
Waged jobs & 24.5 & 35.0 \\
Waged jobs: First Jobs & 32.8 & \\
Same or New Employer & & \\
Regular waged jobs & & 34.4 \\
Waged jobs & 31.3 & 28.6 \\
\hline
\end{tabular}

*Note: This is the percentage acquiring contracts among those who started new jobs in the private non-agricultural sector. Contracts were acquired during 1998-2002 (col 1) or 2004-2008 (col 2). The sample size of those who acquired contracts with the same employer is too small to analyze separately.

It is important to note that acquisition of a job contract not only implies job security but also other important benefits, such as social insurance coverage, paid vacations and sick leave. Almost $92 \%$ of contracted workers have social insurance coverage compared to less than $9 \%$ among non-contracted workers. Furthermore, a similar proportion (92\%) of contracted workers have paid vacation and sick leave, whilst amongst non-contracted workers only $5 \%$ have paid vacation and $9 \%$ have sick leave. ${ }^{12}$ Hence, the attraction of a job contract goes well beyond job security.

${ }^{12}$ These figures are derived from the ELMPS 2012 survey. 


\section{Simple Empirical Analysis of Formalization: Probability of Acquiring a Contract Before and After Enactment of the Law}

To study the effect of the change in labor law, we estimate the probability of acquiring a contract in a job in the private non-agricultural waged sector distinguishing between jobs that started before enactment of the law (1998 to 2002) and jobs that started after the enactment of the law (2004-2008), as follows:

$$
N_{i t}=\alpha+\tau X_{i t}+\beta M_{t}+\lambda L_{i t}+\mu_{i t}
$$

We limit our sample to all jobs that started between 1998-2002 and 2004-2008. We exclude 2003 due to potential anticipation effects as the law was announced in 2003, but became effective in 2004. We construct an unbalanced panel from retrospective data where each observation is an individual i in a year t. $N_{i t}=1$ if the job is contracted and 0 if not. $\mathrm{L}$ is a dummy variable indicating time period where $\mathrm{L}=1$ if the job started in 2004-2008 (the post policy period) and $\mathrm{L}=0$ if the job started in 1998-2002. $X_{i t}$ is a vector of the worker's characteristics such as gender, education level (six levels), age in years, and region of residence (six regions). ${ }^{13} M_{t}$ is a vector of macro and business cycle variables, which includes annual real GDP growth rate and annual unemployment rate.

Table 3 shows the summary results for a linear probability model for whether or not the job is contracted for all waged jobs started in the 1998-2008 period. The first four columns show all jobs regardless of whether they are with a new or the same employer. Columns 5-8 refer to jobs involving a new employer. Columns 9-12 are new jobs for new labor market entrants. As seen, the effect of the labor law captured by the dummy for 2004-2008 is positive and significant throughout. The effect appears to be twice as large for new entrants to the labor market than for all job changers. Indeed, controlling for cyclical or trend factors other than the labor law that could have affected the willingness of employers to provide their workers with contracts, we still find positive and significant effect for the law. We do recognize that these effects could still be attributed to other unobservable factors that are not captured by GDP growth and unemployment, hence, in what follows, we implement policy evaluation techniques, to better identify the causal impact of the policy change.

\footnotetext{
${ }^{13}$ See Appendix Table 1 for the education and region categories.
} 
Table 3: Linear Probability Model : Acquisition of Contract in Jobs* Started During 1998-2002 and 2004-2008

\begin{tabular}{|c|c|c|c|c|c|c|c|c|c|c|c|c|}
\hline & \multicolumn{4}{|c|}{ Same or New Employer } & \multicolumn{4}{|c|}{ New Employer } & \multicolumn{4}{|c|}{ First Jobs } \\
\hline & \multicolumn{2}{|c|}{ Regular Waged } & \multicolumn{2}{|c|}{$\begin{array}{c}\text { All } \\
\text { Waged }\end{array}$} & \multicolumn{2}{|c|}{ Regular Waged } & \multicolumn{2}{|c|}{ All Waged } & \multicolumn{2}{|c|}{ Regular Waged } & \multicolumn{2}{|c|}{ All Waged } \\
\hline & 1 & 2 & 3 & 4 & 5 & 6 & 7 & 8 & 9 & 10 & 11 & 12 \\
\hline \multirow{2}{*}{$\begin{array}{l}\text { Job started } \\
2004-08\end{array}$} & $0.049 * * *$ & $0.054 * * *$ & $0.039 * * *$ & $0.042 * *$ & $0.037 * *$ & $0.044 * * *$ & $0.027 * *$ & $0.045^{*}$ & $0.070 * *$ & $0.078 * *$ & $0.078 * * *$ & $0.087 * * *$ \\
\hline & (3.11) & $(2.81)$ & $(2.98)$ & $(2.65)$ & $(2.32)$ & $(2.27)$ & $(1.90)$ & $(1.76)$ & $(2.07)$ & $(2.04)$ & $(2.61)$ & $(2.57)$ \\
\hline Individual & yes & yes & yes & yes & yes & yes & yes & yes & yes & yes & yes & yes \\
\hline Macro factors & & yes & & yes & & yes & & yes & & yes & & yes \\
\hline $\mathrm{R}^{2}$ & 0.055 & 0.055 & 0.071 & 0.071 & 0.063 & 0.063 & 0.080 & 0.080 & 0.067 & 0.067 & 0.092 & 0.093 \\
\hline $\begin{array}{l}\text { No. of observations } \\
\text { (individual/year) }\end{array}$ & 3271 & 3271 & 4209 & 4209 & 3145 & 3145 & 4078 & 4078 & 1164 & 1164 & 1383 & 1383 \\
\hline
\end{tabular}

Note: t-statistics in parentheses. *The incidence of acquisition of contract in jobs in private non-agriculture waged sector. Individual Characteristics: gender, education (six categories), age and region of residence (six regions). Macro factors: annual real GDP growth rate and annual unemployment rate. All waged include regular and irregular waged jobs. 


\section{Identifying the Effect of the Change in Labor Law: A Difference in Difference Approach}

\subsection{Set-Up and Identifying Assumption}

To test whether the change in labor law has increased the incidence of acquiring job contracts, we use difference in difference (DiD) estimation. We compare the two periods before and after the change in law for two groups of workers, whom we posit would be differently affected by the passage of the law. To be more specific, we study those who started a job but had no contract at the beginning of the period and investigate whether they had acquired a contracted job up to 5 years later. We first distinguish private non-agricultural wage workers by the period in which they started their jobs. First, there are those who started a non-contracted job between 1996 and 1998, whom we observe over the subsequent 5 years, (1998-2002) to see if they acquired contracts. Second is the group who started non-contracted jobs between 2002 and 2004 and whom we observe over the subsequent 5 years, (2004-2008) to see if they acquired contracts. The second difference is captured by identifying two groups of workers whom we posit will be differently affected by the law. The first group, whom we posit will be fully affected is made up of initially non-contracted workers who start the respective period working for formal or semi-formal firms (which we refer to as type $\mathrm{F}$ and consider our treatment group). The second group, which can only be indirectly affected by the law is made up of initially non-contracted workers who start by being initially employed in informal firms (which we refer to as type I and consider our comparison group). The formality status of the firm is determined by whether any other workers in the firm have either a contract or social insurance. If at least one other worker has either, the firm is considered formal or semi-formal. The only ways a type I worker can be affected by the law is either by changing jobs to join a formal firm or if the informal firm in which s/he works formalizes. Because both these things are possible, albeit improbable given the low rate of job transitions in the Egyptian labor market, our estimates of the effects of the law using this DiD set up will likely be downward biased and thus conservative.

It is important to note here that we set up our $\mathrm{DiD}$ in a way that allows us to compare the change into a contracted job in two periods to control for confounding factors related to transition from a non-contract state to a contract state. Our identification strategy is based on the assumption that if the supply of good private sector jobs is simply changing due to macroeconomic factors or other factors related to business climate, these jobs would be equally accessible to workers who are initially employed in formal firms or informal firms. However, reforms that reduce the cost of employment formality for formal employers will differentially affect workers employed informally in such firms compared to those employed in informal firms.

Figure A1 shows the number of new jobs in F \& I firms by year of job start. It shows the trends in job creation for the two types of workers. As shown, both groups have had very similar patterns albeit the number of I jobs is much higher than the number of $F$ jobs. In order to check the common trend assumption for type $\mathrm{F}$ and I workers, Figure A2 provides the share of new contracted jobs in F \& I firms by year of job start, and it reassures us that using I, as a comparison group, is justified. 


\subsection{Difference in Differences Analysis}

We construct an unbalanced panel of annual job statuses and characteristics for both time periods and we us it to estimate the following model:

$$
\text { Contract }_{i t}=\alpha+\beta \text { Treated }_{i t}+\gamma \text { Post }_{t}+\text { STreated }_{i t} \text { Post }_{t}+\phi X_{i t}+\varepsilon_{i t}
$$

where our outcome of interest Contract it is contract holding of individual $\mathrm{i}$ at time $\mathrm{t}$, Contract $_{i t}=0$ when individual $\mathrm{i}$ does not hold a contract at time $\mathrm{t}$ and Contract $_{i t}=1$ otherwise. T refers to Treatment. We define the treated group $(T=1)$ as those working for formal/semi-formal employers (F) whilst the comparison group $(\mathrm{T}=0)$ are those employed by informal employers (I). Post refers to the post policy change period, and gets the value Post=1 for 2004-2008 and Post=0 for 1998-2002. Our Difference-inDifferences estimate of the effect of the law is captured by the coefficient $\delta$ of the interaction term Treated*Post. $\mathrm{X}$ is a vector of individual characteristics, macroeconomic variables such as annual GDP growth rates and annual unemployment rates, and time trend terms capturing the time since the job started. A fundamental assumption here is that trends would have been the same for the treatment and control groups in the absence of the policy change.

Figure A3 presents graphically the impact of the law. The dashed line is the share of contract jobs for Type I, the control group. The solid line is the share of contract jobs for our treatment group (Type F). The dotted black line is the assumed counterfactual, depicting what would have happened to the treatment group in the absence of the law if they changed at the same rate as the control group (i.e. at 2\%). Hence, the distance between the solid and the dotted lines is $\delta$. In relative terms, this is a $34 \%$ net increase in the share of contract jobs for the Treatment group from before to after the law.

Table 4 presents the estimates of the difference in differences models. Panel A shows the estimates without any covariates. Panel B controls for the individual characteristics, which are time variant such as age and region of residence. Panel $\mathrm{C}$ shows the estimates controlling for individual and macroeconomic trends (such as annual real GDP growth rate and annual unemployment rate) and Panel D the estimates that control for time trends, which is a linear trend, as well. The estimates show that the effect of the law, $\delta$ (captured in the last column by the Diff in Diff), is positive and significant. In fact controlling for individual characteristics increases the magnitude of the effects of the law, but unsurprisingly controlling for the macroeconomic trends and time trends reduces that magnitude but not substantially.

To sum up, our various tests support our hypothesis that the law had a positive impact on contract acquisition. The magnitude of the effect is that the share of contract jobs increased among workers in the F firms by 3.4 to 3.9 percentage points more than for workers in the I firms as a result of the law. Given that around $15 \%$ of $F$ firm workers were non-contracted prior to the introduction of the law, this represents a relative decrease of between $23 \%-26 \%$ that can be attributed to the law. This result is quite robust to changes in specification and to the inclusion of trend lines and macroeconomic variables. 
Table 4: Difference in Differences Estimation: Determinants of Acquiring Job Contract

\begin{tabular}{|c|c|c|c|c|c|c|c|}
\hline & \multicolumn{3}{|c|}{ Base Line: 1998-2002 } & \multicolumn{4}{|c|}{ Post : 2004-2008 } \\
\hline Outcome & $\begin{array}{c}\text { Control } \\
\alpha\end{array}$ & $\begin{array}{c}\text { Treated } \\
\alpha+\beta\end{array}$ & $\begin{array}{c}\text { Diff } \\
\beta\end{array}$ & $\begin{array}{c}\text { Control } \\
\alpha+\gamma\end{array}$ & $\begin{array}{c}\text { Treated } \\
\alpha+\beta+\gamma+\delta\end{array}$ & $\begin{array}{l}\text { Diff } \\
\beta+\delta\end{array}$ & $\begin{array}{c}\text { Diff in } \\
\text { Diff } \\
\delta\end{array}$ \\
\hline
\end{tabular}

\begin{tabular}{l|lllllll} 
Coef & $0.075^{* * *}$ & 0.091 & 0.017 & $-0.062^{* * *}$ & $0.114^{* * *}$ & $0.052^{* * *}$ & $0.036^{*}$ \\
t-statistics & 14.02 & 1.36 & 1.19 & -2.43 & 3.23 & 2.90 & 1.89
\end{tabular}

Panel B: Controlling for Individual Characteristics

\begin{tabular}{l|lllllll} 
Coef & 0.012 & 0.010 & -0.002 & -0.008 & $0.029^{* * *}$ & $0.037 * * *$ & $0.039 * *$ \\
t-statistics & 0.72 & -0.08 & -0.13 & -1.18 & 2.09 & 3.16 & 2.10
\end{tabular}

Panel C: Controlling for Individual Characteristics and Macroeconomic factors

\begin{tabular}{l|lllllll} 
Coef & $0.176^{* * *}$ & 0.175 & -0.001 & 0.178 & 0.215 & $0.037^{* * *}$ & $0.038^{* *}$ \\
t-statistics & 2.58 & 0.16 & -0.08 & 0.20 & 0.66 & 3.13 & 2.08
\end{tabular}

Panel D: Controlling for Individual Characteristics, Macroeconomic factors and time trend

\begin{tabular}{l|lllllll} 
Coef & 0.002 & 0.004 & 0.002 & -0.018 & 0.018 & $0.036^{* * *}$ & $0.034^{*}$ \\
t-statistics & 0.03 & 0.03 & 0.13 & -0.25 & 0.41 & 2.82 & 1.87 \\
\hline
\end{tabular}

*Note: $\mathrm{N}=6082$ in Panel A, N=6060 in Panels B-D. Outcome: Acquiring contract in private nonagriculture regular waged job. Individual Characteristics (time variant): age and region of residence. Macro factors: annual real GDP growth rate and annual unemployment rate.

\section{3 Using Matching Difference in Difference Estimator}

One potential threat to identification is the fact that our 'treatment' and 'control' groups (initially non-contracted workers in F and I firms, respectively) may be different on a number of dimensions. We use the Matching Difference in Difference Estimator (MDiD) to partially address this concern by making the treatment and control observations similar at least on dimensions related to the observable characteristics of the workers. Matching estimators evaluate the effects of a policy change by comparing outcomes for treated persons to untreated individuals of similar observed characteristics in a comparison group. ${ }^{14}$ As before, a treated observation is defined as an initially noncontracted worker in a formal form ( $\mathrm{T}=1$ if Type $\mathrm{F}$ ). Each treaded observation is matched using kernel propensity score matching to a group of matched comparison observations, namely initially non-contracted workers in informal firms (Type I). The outcome of interest is whether these initially non-contracted workers obtained a contract over a five-year period. Our difference-in-difference estimator of the effect of the law is the difference in outcome between treated and matched controls in a postpolicy period (2004-2008) minus the difference between treated and control in a pre-

\footnotetext{
${ }^{14}$ Matching Difference in Difference was introduced by Heckman, Ichimura, and Todd (1997) and Heckman, Ichimura, Smith, and Todd (1998).
} 
policy period (1998-2002). We report the average treatment effect on the treated (ATT), which is given by:

$$
\begin{aligned}
& A T T=\frac{1}{n_{T 1}} \sum_{i \in\{T=1\}}\left(C_{i 1}-\sum_{j \epsilon\{T=0\}} W_{1}(i, j) C_{j 1}\right)-\frac{1}{n_{T 0}} \sum_{i \epsilon\{T=1\}}\left(C_{i 0}-\right. \\
& \left.\sum_{j \epsilon\{T=0\}} W_{0}(i, j) C_{j 0}\right)
\end{aligned}
$$

where $C_{i t}=1$ if the individual acquires a contract over period $\mathrm{t}$ ( $=1$ for post and $=0$ for pre), $n_{T t}$ is the number of treated observations in period $t$, and $W_{t}(i, j)$ are weights obtained from the kernel function used to weight each comparison observation $\mathrm{j}$ in the vicinity of each treated observation i. The reported estimates use a Gaussian kernel function. ${ }^{15}$

Propensity scores are predicted using a probit model for the probability of treatment as a function of workers' observable characteristics at the time they started a job: 199698 for the pre-Policy period and 2002-04 for the post-Policy period. Recall that we study those who started a job but had no contract at the beginning of the period and investigate whether they had acquired a contracted job within the next 5 years, namely over the period 1998-2002 or 2004-2008. We use the same individual characteristics we used in the regression-based estimates above, namely sex, age, education (6 categories) and region (6 categories). The probit model estimates for each of the two time periods are shown in Table A1 in the appendix. As suggested by Rosenbaum and Rubin (1985) a test based on the comparison of means for each covariate between treated and matched controls is performed to determine whether the two groups are balanced with regard to pre-treatment covariates. T-tests of the means of covariates across the treatment and matched controls reveal that matching achieved covariate balance separately for the pre- and post-policy periods. The tests are shown in table A2.

The Difference in Differences analysis is performed on the treatment and control observations that are on the common support in each of the two time periods. Table 5 shows the estimated difference between the matched treatment and control group (MDiff) is zero in the pre-policy period, i.e. there is no effect in the pre-policy period. The matched difference is positive and significant in the post-policy period and so is the difference-in-difference (MDiD), showing that the introduction of the law has increased the probability of transitioning from a non-contracted status to contracted status by 3.3 percentage points for workers employed in formal firms. This represents a relative reduction of non-contracted workers by around 22\%. Overall, the Matching Difference in Differences results are consistent and are of similar magnitude to our earlier findings.

\footnotetext{
${ }^{15}$ A bandwith of 0.05 is used. For robustness we have also used Epanechnikov Kernel Matching and the estimates were robust to the choice of kernel function.
} 
Table 5: Matching Difference in Differences Estimates

\begin{tabular}{|c|c|c|c|c|c|c|c|}
\hline \multirow[b]{2}{*}{ Outcome } & \multicolumn{3}{|c|}{ Pre: 1998-2002 } & \multicolumn{4}{|c|}{ Post : 2004-2008 } \\
\hline & $\begin{array}{c}\text { Matched } \\
\text { Control }\end{array}$ & $\begin{array}{c}\text { Matched } \\
\text { Treated }\end{array}$ & MDiff & $\begin{array}{c}\text { Matched } \\
\text { Control }\end{array}$ & $\begin{array}{c}\text { Matched } \\
\text { Treated }\end{array}$ & MDiff & MDiD \\
\hline Coef & 0.093 & 0.093 & -0.000 & 0.082 & 0.114 & $0.033 * * *$ & $0.033^{* *}$ \\
\hline t-statistics & & & -0.030 & & & 3.27 & 2.16 \\
\hline
\end{tabular}

*Note: Number of matched observations with common support: in Baseline: 2713 (T=394) and in Post: 3246 ( $\mathrm{T}=533)$. Outcome: Acquiring contract in private non-agriculture regular waged job.

\section{Further Robustness: Formality}

As a further robustness check we focus here on formality by examining the incidence of job contract holding.

\subsection{The Incidence of Formality}

When examining existing regular waged workers regardless of when they started their jobs, a similar pattern is observed: the share of contracted regular workers increased from 33\% to $35 \%$ between those two periods as shown in Table 6. A similar increase is also seen for all (regular and irregular) waged workers in the post-law period. Thus, the preponderance of this evidence suggests that there has been an increase in contracted jobs after the law was passed compared to before it.

Table 6: Percentage of Job/Year covered by a Contract: 1998-2002 vs 2004-2008

\begin{tabular}{l|cc}
\hline & $\mathbf{1 9 9 8 - 2 0 0 2}$ & $\mathbf{2 0 0 4 - 2 0 0 8}$ \\
\hline Regular Waged Jobs & 32.9 & 35.2 \\
Waged Jobs & 24.5 & 26.1 \\
\hline \multicolumn{2}{c}{ Note: This is an unbalanced panel of jobs per year, where the proportions of annual contracted jobs }
\end{tabular}
are averaged over 1998-2002 in col 1 and over 2004-2008 in col 2.

\subsection{Probability of Formality: Before \& After the Law Using Panel Data Models}

We examine the probability of a worker holding a job contract before and after the law regardless of the starting date of the job. We create an unbalanced panel of those employed in the private waged sector at any point of time between 1998 and 2008, and estimate the probability of holding a contracted job using the following linear probability model:

$$
J_{i t}=\alpha+\rho X_{i t}+\beta M_{t}+\sigma L_{i t}+\eta_{i t}
$$

Where $\mathrm{J}_{\text {it }}$ refers to the waged job of individual $\mathrm{i}$ at time $\mathrm{t}$ and $\mathrm{J}_{\mathrm{it}}=1$ if the job is contracted and $\mathrm{J}_{\mathrm{it}}=0$ if not. $\mathrm{L}$ captures the effect of the labor law and $\mathrm{L}=1$ if $\mathrm{t}=2004-2008$ (post-law period) and $\mathrm{L}=0$ if $\mathrm{t}=1998-2002$ (pre-law period). As before, $\mathrm{X}_{\mathrm{it}}$ is a vector of the worker's characteristics such as gender, education, age and region, and $\mathrm{M}_{t}$ are macro 
factors: annual real GDP growth rate and annual unemployment rate. We estimate both random effects (RE) and fixed effects (FE) panel data models. Table 7 shows the determinants of holding a job contract in all waged jobs and in regular waged jobs. In both cases, both the RE \& FE models suggest that the change in the probability of holding a contracted job after the enactment of the law is positive and significant even after controlling for macroeconomic factors. Indeed, the predicted probability of holding a contract is about two percentage points higher after the law than before it (22\% vs $20 \%$ ) which is equivalent to a 10 percent relative increase.

Table 7: Linear Probability Panel Model of Holding Job Contract: 19982008

\begin{tabular}{|c|c|c|c|c|c|c|c|c|}
\hline & \multicolumn{4}{|c|}{ Regular Waged Job } & \multicolumn{4}{|c|}{ Waged Job } \\
\hline & \multicolumn{2}{|c|}{$\mathbf{R E}$} & \multicolumn{2}{|c|}{ FE } & \multicolumn{2}{|c|}{ RE } & \multicolumn{2}{|c|}{ FE } \\
\hline & 1 & 2 & 3 & 4 & 5 & 6 & 7 & 8 \\
\hline After the law: & $0.020^{* * *}$ & $0.016^{* * *}$ & $0.021 * * *$ & $0.016^{* * *}$ & $0.018^{* * *}$ & $0.015^{* * *}$ & $0.019 * * *$ & $0.016^{* * *}$ \\
\hline & $(13.91)$ & (6.06) & $(14.21)$ & $(6.22)$ & $(15.23)$ & (7.11) & (15.69) & $(7.35)$ \\
\hline $\begin{array}{l}\text { Individual } \\
\text { Controls }\end{array}$ & Yes & Yes & Yes & Yes & Yes & Yes & Yes & Yes \\
\hline Macro Factors & & Yes & & Yes & & Yes & & Yes \\
\hline $\mathrm{R}^{2}$ & 0.115 & 0.115 & & & 0.149 & 0.149 & & \\
\hline F-statistics & & & 134.36 & 134.37 & & & 114.09 & 114.09 \\
\hline No of obs & 25921 & 25921 & 25938 & 25938 & 37285 & 37285 & 37317 & 37317 \\
\hline
\end{tabular}

Note: t-statistics in parentheses. Individual controls are gender, education, age and region of residence in RE models and only age in FE models. Macro factors are annual real GDP growth rate and annual unemployment rate. RE are estimates from random effect model \& FE are estimates from a fixed effects model.

To sum up, our results suggest that there has been an increase in the incidence of contract job holding, after the law was enacted, even after controlling for individual fixed effects and macro trends. This provides further evidence on the impacts of the law as the previous section studies the incidence of contract acquisition, whilst this section examines the incidence of job holding. Hence, we observe the effects of the law on the flows and the stocks of contracted jobs.

\section{Conclusion}

This paper examines the effect of a change in employment protection legislation on formal employment. We use the case of Egypt, where labor market informality is substantial and the introduction of a new labor law in 2003 enables us to study the impact of more flexible labor market regulations on the incidence of formal employment as measured by the presence of a legal job contract.

We use various techniques to estimate the causal impact of the change in the labor law. We confine our analysis to the period between 1998-2008 to construct 5-year periods before and after the law. We first exploit the temporal change in the law and 
examine changes in the contract status of waged workers in new jobs as well as in all jobs in the private non-agricultural sector. Our simple models show an increase in the incidence of acquisition of contracted jobs after the law was implemented compared to the previous period, even after controlling for macro confounding factors.

We also use Difference in Differences methods and matching with Difference in Differences to disentangle the causal impact of the law. In order to find a comparison group, we argue that non-contracted workers who worked for formal/semi-formal employers where other co-workers are contracted and covered by social security would be directly affected by the change in law. On the other hand, those non-contracted workers working for informal employers where all other co-workers have no job contracts and no social security coverage would only be indirectly and weakly affected by the change in law given the fact that they would either need to change employers or their employers would need to formalize themselves, which is much less likely. Our estimates are therefore likely to be understated, given that our comparison group is likely to be partially affected by the law.

Our findings indicate that the incidence of acquiring contract in new jobs have increased after the introduction of this law. The results suggest that the change in law has had a positive impact on formalization of employment and has reduced informal employment, measured as waged jobs without contracts. The passage of the new labor law did in fact increase the probability of transitioning to formal employment for noncontractual workers employed in formal firms by about 3-3.5 percentage points, or the equivalent to at least a fifth of informal workers in formal firms. Thus, our findings support the hypothesis that less rigid labor market regulations increase formal employment.

The findings are encouraging since they indicate that labor flexibility increases formal employment in a context where informality is widespread. Those results should encourage further labor reforms to increase flexibility in the labor market, such as reducing the social security contribution by employers and workers to attempt to reduce informalization and improve the quality of employment for unprotected workers. However, policy-makers must recognize that labor regulations are only one part of the broader economic policy framework. Its interaction with the regulation of product markets, macroeconomic policy, and the business investment climate will determine the overall labor market performance. 


\section{References}

Angel-Urdinola, D. and A. Kuddo. 2010 "Key Characteristics of Employment

Regulations in the Middle East and North Africa." World Bank SP Discussion

Paper 1006. Washington DC: The World Bank.

Assaad, R. 2004 Country Overview on Labor Market Policies in Egypt, European

Training Foundation. Mimeo.

Assaad, R. 2009. "Labor Supply, Employment and Unemployment in the Egyptian Economy, 1988-2006. In Ragui Assaad (Ed.), The Egyptian Labor Market Revisited, pp. 1-52. Cairo: American University in Cairo Press, pp. 1-52.

Assaad, R. and C. Krafft 2013. The Egypt Labour Market Panel Survey: Introducing the 2012 Round, IZA Journal of Labor \& Development, 2:8.

Assaad, R. and C. Krafft 2015, "The Structure and Evolution of Employment in Egypt: 1998-2012.” In The Egyptian Labor Market in an Era of Revolution. R. Assaad and C. Krafft (Eds.). Oxford: Oxford University Press, pp. 27-51.

Assaad, R., C. Krafft, and C. Yassine. 2015. "Comparing Retrospective and Panel Data Collection Methods to Assess Labor Market Dynamics.” Paper presented at the ERF Research Workshop on Labor Market Dynamics in the Middle East and North Africa. The Economic Research Forum, Cairo. Mimeo.

Bentolila, Samuel and Guiseppe Bertola. 1990. "Firing Costs and Labour Demand: How Bad is Eurosclerosis?” Review of Economic Studies. 57 (3): 381-402

Besley, T. and R. Burgess. 2004. "Can Labour Regulation Hinder Economic Performance? Evidence from India." Quarterly Journal of Economics, CXIX (1): 91-134.

Betcherman, G., A. Luinstra, and M. Ogawa. 2001. "Labor Market Regulation: International Experience in Promoting Employment and Social Protection.” The World Bank, Social Protection Discussion Paper Series, no. 0128.

Betcherman, G. 2015. "Labor Market Regulations: What do we know about their Impacts in Developing Countries?” World Bank Research Observer. 30: 124 153.

Blanchard, Olivier and Portugal, Pedro, 2001. "What Hides Behind an Unemployment Rate: Comparing Portuguese and U.S. Labor Markets." American Economic Review, 91: 187-207.

Botero, Juan, Djankov, Simeon, La Porta, Rafael, Lopez-de-Silanes, Florencio, Shleifer, Andrei, 2004. "The regulation of labour." Quarterly Journal of Economics 119 (3), 1339-1382.

Djankov, Simeon and Ramalho, Rita, 2009. "Employment laws in developing countries," Journal of Comparative Economics, 37(1): 3-13.

Di Tella, R. and R. MacCulloch. 2005. "The consequences of labor market flexibility: Panel evidence based on survey data." European Economic Review 49 (5): 122559.

ERF. 2012. The Egypt Labor Market Panel Survey of 2012. Economic Research Forum, Cairo, Egypt [www.erfdataportal.com]

Freeman, Richard. 1993. "Labor market institutions and policies: help or hindrance to economic development?" Proceedings of the World Bank Annual Conference on Development Economics 1992.

Gatti R., D. Angel-Urdinola, J. Silva, and A. Bodor, 2011. Striving for Better Jobs. The Challenges of Informality in Middle East and North Africa Region. Washington, DC: World Bank, Directions in Development, No: 90271 
Heckman, J. J., Ichimura, H., Smith, J. A. and Todd, P. E. 1998. "Characterizing Selection Bias Using Experimental Data,” Econometrica, 66: 1017-1099.

Heckman, J. J., Ichimura, H., and Todd, P. E. 1997. "Matching as an Econometric Evaluation Estimator: Evidence from Evaluating a Job Training Programme," The Review of Economic Studies, 64(4): 605-654.

Heckman, J.J. and Pagés, C. (eds.), (2004), Law and Employment: Lessons from Latin America and the Caribbean, Chicago: University of Chicago Press.

Hopenhayn, Hugo and Richard Rogerson. (1993) Job Turnover and Policy Evaluation: A General Equilibrium Analysis. Journal of Political Economy. 101 (5): 915-938.

Kingdon, G., J. Sandefur, and F. Teal, 2006. "Labor Market Flexibility, Wages and Incomes in Sub-Saharan Africa in the 1990s.” African Development Review 18 (3): 392-427.

Kugler, A. 2004. "The Effect of Job Security Regulations on Labor Market Flexibility: Evidence from the Colombian Labor Market Reform.” In J. Heckman and C. Pages (eds). Law and Employment: Lessons from Latin America and the Caribbean. Cambridge, MA: NBER and Chicago, IL: University of Chicago, pp.183-228.

Lazear, E. 1990. “Job security provisions and employment.” Quarterly Journal of Economics 105 (3): 699-726.

Moktar, M. and Wahba, J. 2000. "Informalization of Labor in Egypt.” In The Labor Market in a Reforming Economy: Egypt in the 1990s, edited by R. Assaad. Cairo and New York: The American University in Cairo Press, 2002, pp.131-157.

Rosenbaum, P.R. und D.B. Rubin 1983. "The Central Role of the Propensity Score in Observational Studies for Causal Effects”, Biometrika 70 (1), S.1-55.

Rosenbaum, P. and Rubin, D. 1985, “Constructing a Control Group Using Multivariate Matched Sampling Methods that Incorporate the Propensity Score", American Statistician, 39-38.

Roushdy, R., and Gadallah, M. 2011, "Labor market adjustment to the world financial crisis: Evidence from Egypt.” Economic Research Forum Working Paper (No. 643).

Wahba, J. 2009. “The Impact of Labor Market Reforms on Informality in Egypt”. Gender and Work in the MENA Region Working Papers Series. Number 3, The Population Council, Cairo. Egypt.

World Bank 2008. Doing Business 2009. Washington DC: The World Bank and the International Finance Corporation. [http://www.doingbusiness.org/reports/globalreports/doing-business-2009]. 


\section{APPENDIX}

Table A1: Propensity Score Estimates

\begin{tabular}{lcccr}
\hline & \multicolumn{2}{c}{ Pre-Law } & \multicolumn{2}{c}{ Post-Law } \\
\hline male & Coeff & t-statistics & Coeff & t-statistics \\
\hline age & -0.208 & -2.26 & -0.445 & -6.24 \\
Education (illiterate is the reference) & 0.017 & 3.08 & 0.009 & 1.79 \\
Less than Primary & -0.257 & & & \\
Primary & 0.344 & -0.95 & -0.806 & -3.05 \\
Intermediate & 0.726 & 4.92 & -0.098 & -0.80 \\
Secondary School & 0.394 & 1.82 & -0.180 & -0.17 \\
University & 0.741 & 4.65 & -0.055 & -0.31 \\
Region of residence (Greater Cairo is the reference) & 0.220 & 1.87 \\
Alex. \& Canal Cities & 0.087 & 0.84 & & \\
Lower Urban & -0.406 & -3.60 & -0.224 & -2.45 \\
Upper Urban & -0.657 & -5.30 & -0.456 & -5.31 \\
Lower Rural & -0.188 & -2.13 & -0.377 & -4.68 \\
Upper Rural & -0.536 & -4.72 & -0.552 & -4.84 \\
\hline
\end{tabular}

Note: This is the first stage of the MDiD- based on Kernel Matching.

Table A2: T-tests of the means of covariates across the treatment and matched controls

\begin{tabular}{|c|c|c|c|c|c|c|c|c|c|c|}
\hline \multicolumn{4}{|c|}{ Pre-law } & & \multicolumn{6}{|c|}{ Post-law } \\
\hline \multirow[b]{2}{*}{ Variable } & \multicolumn{3}{|c|}{ Mean } & \multicolumn{2}{|c|}{ t-statistics } & \multicolumn{3}{|c|}{ Mean } & \multicolumn{2}{|c|}{ t-statistics } \\
\hline & Treated & Control & $\begin{array}{c}\% \\
\text { biased }\end{array}$ & $\mathrm{t}$ & $\mathrm{p}>\mathrm{t}$ & Treated & Control & $\begin{array}{c}\% \\
\text { biased }\end{array}$ & $\mathrm{t}$ & $\mathrm{p}>\mathrm{t}$ \\
\hline male & 0.840 & 0.873 & -9.8 & -1.33 & 0.183 & 0.754 & 0.801 & -12.3 & -1.83 & 0.067 \\
\hline age & 24.563 & 24.337 & 3.9 & 0.55 & 0.585 & 24.726 & 24.542 & 3.4 & 0.55 & 0.582 \\
\hline \multicolumn{11}{|l|}{ Education } \\
\hline Primary & 0.010 & 0.015 & -2.9 & -0.57 & 0.566 & 0.008 & 0.007 & 0.2 & 0.06 & 0.951 \\
\hline Primary & 0.154 & 0.178 & -5.9 & -0.86 & 0.393 & 0.131 & 0.149 & -5.0 & -0.83 & 0.404 \\
\hline $\begin{array}{l}\text { Intermediate } \\
\text { Secondary }\end{array}$ & 0.571 & 0.563 & 1.7 & 0.24 & 0.810 & 0.492 & 0.509 & -3.5 & -0.58 & 0.565 \\
\hline School & 0.033 & 0.032 & 0.3 & 0.05 & 0.962 & 0.036 & 0.037 & -0.5 & -0.07 & 0.940 \\
\hline University & 0.198 & 0.169 & 8.0 & 1.06 & 0.289 & 0.263 & 0.226 & 9.0 & 1.38 & 0.169 \\
\hline \multicolumn{11}{|c|}{$\begin{array}{l}\text { Region of residence } \\
\text { Alex \& Canal }\end{array}$} \\
\hline Cities & 0.185 & 0.150 & 9.9 & 1.31 & 0.191 & 0.154 & 0.160 & -1.8 & -0.28 & 0.781 \\
\hline Lower Urban & 0.104 & 0.112 & -2.5 & -0.36 & 0.716 & 0.073 & 0.086 & -4.3 & -0.74 & 0.457 \\
\hline Upper Urban & 0.063 & 0.077 & -4.6 & -0.74 & 0.458 & 0.103 & 0.113 & -2.9 & -0.50 & 0.614 \\
\hline Lower Rural & 0.302 & 0.317 & -3.2 & -0.45 & 0.654 & 0.261 & 0.267 & 1.5 & 0.24 & 0.807 \\
\hline Upper Rural & 0.094 & 0.108 & -4.2 & -0.66 & 0.507 & 0.111 & 0.127 & -4.5 & -0.80 & 0.424 \\
\hline
\end{tabular}

Note: T-tests show that matching achieved covariate balance. 


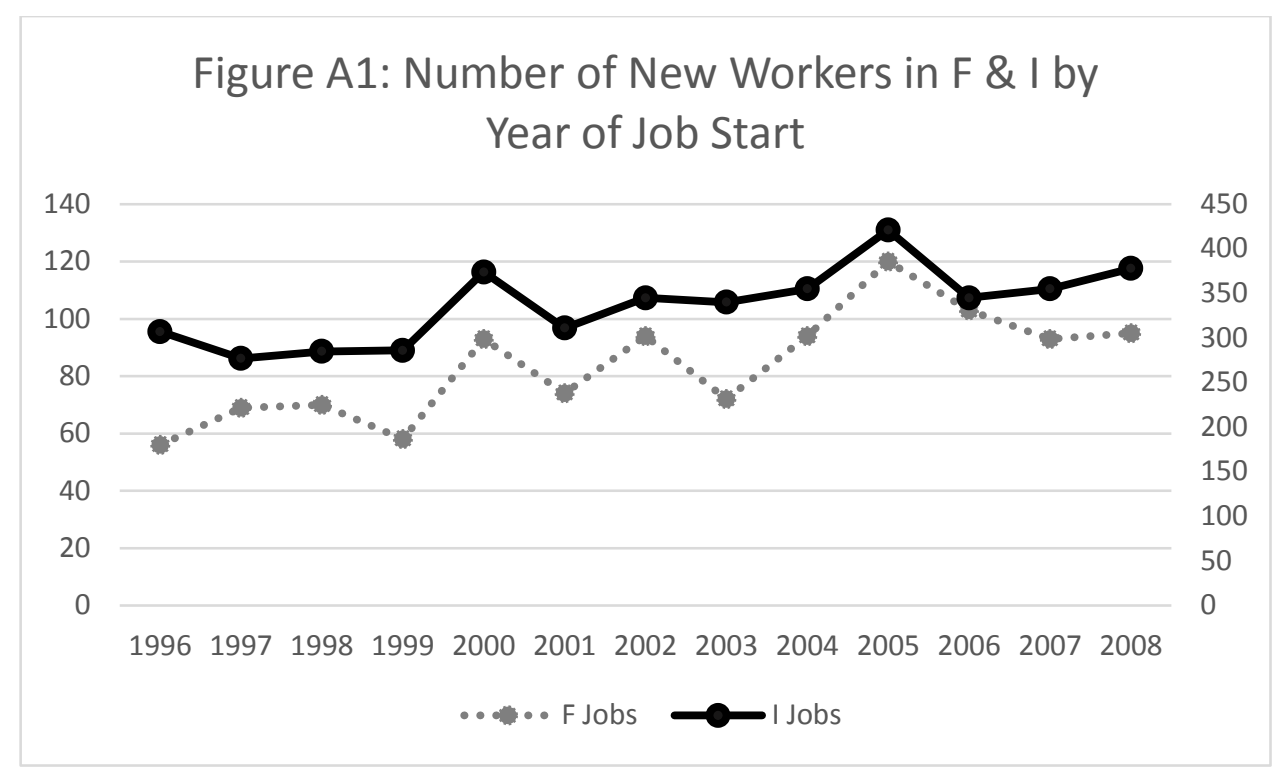

Notes: F jobs are jobs in Formal/semi-formal firms. I jobs are jobs in Informal firms.

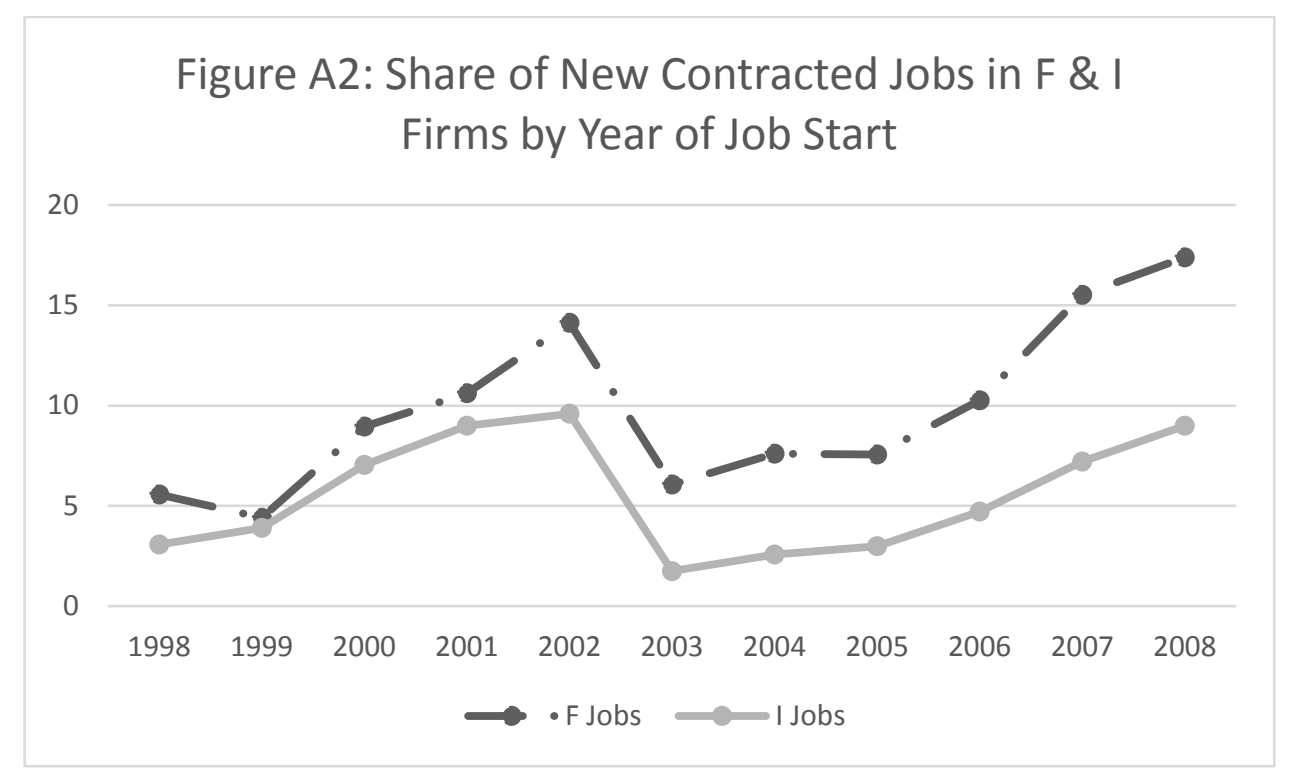

Notes: F jobs are jobes in Formal/semi-formal firms. I jobs are jobs in Informal firms. 


\section{Figure A3: Share of New Contracted Jobs in T \& C : Before \& After}

70

60

50

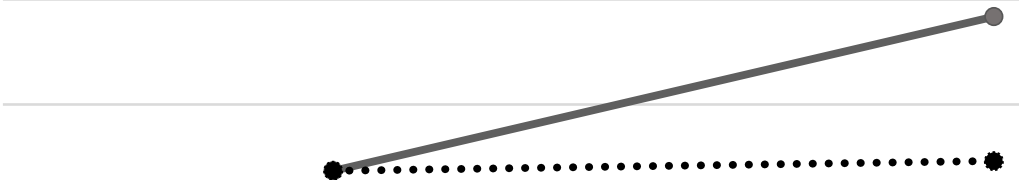

40

30

-

20

10

$1998-2002$

2004-2008

$\longrightarrow$ F Jobs $(\mathrm{T}) \quad-\infty$ I Jobs $(\mathrm{C}) \quad \ldots$ Hypothetical F Jobs $\left(\mathrm{T}^{\prime}\right)$

Notes: F jobs are jobs in Formal/semi-fromal firms, Treatment group. I jobs are jobs in Informal firms, Control Group. Hypothetical F Jobs : jobs in Formal/Semi-Formal firms in the absence of the law. Shares are aggregate of new contracted jobs that started in 1998-2002 or 2004-08. 